\title{
ERRATUM
}

\section{Application of Water Super Absorbents in Waste Air Biofiltration}

\author{
Mohsen Akbari, Mohammad Hassan Fazaelipoor, and Ataallah Soltani Goharrizi
}

Received: 20 April 2010 / Revised: 14 August 2010 / Accepted: 26 October 2010

(C) The Korean Society for Biotechnology and Bioengineering and Springer 2011

In the 2011 issue of Biotechnology and Bioprocess Engineering (BBE), an error occurred in the research article: Mohsen Akbari, Mohammad Hassan Fazaelipoor, and Ataollah Soltai Goharizi (2011) Application of Water Super Absorbents in Waste Air Biofiltration. Biotechnol. Bioprocess Eng. 16: 407-412.

- In the authors's name

Original wording:

Ataollah Soltai Goharizi

This should be replaced by:

Ataallah Soltani Goharrizi

Received: 30 April 2011

Mohsen Akbari, Mohammad Hassan Fazaelipoor*, Ataallah Soltani Goharrizi Department of Chemical Engineering, Faculty of Engineering, Shahid

Bahonar University of Kerman, Kerman, Iran

Tel: +98-341-226-2916, Fax: +98-341-211-8298

E-mail: fazaelipoor@mail.uk.ac.ir, fazaelipoor@yahoo.com

Mohsen Akbari, Ataallah Soltani Goharrizi

International Center for Science, High Technology and Environmental

Sciences, Mahan, Kerman, Iran 